\title{
ENSINO DE HISTÓRIA E LEI 11.645: ANÁLISE DAS COLEÇÕES DIDÁTICAS PNLD 2015
}

\author{
Rafaela Albergaria Mello ${ }^{1}$
}

\begin{abstract}
RESUMO: Esse artigo tem como objetivo apresentar uma parte da pesquisa realizada no Mestrado Profissional em Práticas de Educação Básica do Colégio Pedro II, no qual se procurou investigar o guia ao professor do Plano Nacional do Livro Didático (PNLD) de História para o ensino médio de 2015 , de acordo com a lei $11.645 / 2008$, que é um marco no qual se torna obrigatória a inserção da temática indígena na educação básica. $O$ artigo ainda expõe a importância da temática indígena no ensino de história e faz um breve balanço da política pública do PNLD e da relevância do livro didático na educação.

Palavras-chave: Ensino de história. Índios no Brasil. Livro didático. Conteúdos curriculares.e.
\end{abstract}

TEACHING OF HISTORY AND LAW 11.645: ANALYSIS OF DIDACTIC COLLECTIONS PNLD 2015

ABSTRACT: This article aims to present a part of the research carried out in the Professional Masters in Basic Education Practices of the Pedro II College, in which it was sought to investigate the guide to the teacher of the National Plan of the Didactic Book (PNLD) of History for the high school of 2015, according to Law $1145 / 2008$, which is a framework in which the insertion of the indigenous theme in basic education becomes mandatory. The article also exposes the importance of the indigenous theme in the teaching of history and gives a brief review of the public policy of the PNLD and the relevance of the textbook in education.

Keywords: History teaching. Indians in Brazil. Textbook. Curricular contents.

\section{ENSEÑANZA DE HISTORIA Y LEY 11.645: ANÁLISIS DE LAS COLECCIONES DIDÁCTICAS PNLD 2015}

RESUMEN: Este artículo tiene como objetivo presentar una parte de la investigación realizada en el Máster Profesional en Prácticas de Educación Básica del Colegio Pedro II, en el cual se buscó investigar el guía al profesor del Plan Nacional del Libro Didáctico (PNLD) de Historia para la enseñanza media de 2015, de acuerdo con la ley 11.645/2008, que es un marco en el que se torna obligatoria la inserción de la temática indígena en la educación básica. El artículo aún expone la importancia de la temática indígena en la enseñanza de historia y hace un breve balance de la política pública del PNLD y de la relevancia del libro didáctico en la educación.

Palabras clave: Enseñanza de historia. Indios en Brasil. Libro didáctico. Contenidos curriculares. 


\section{Introdução}

Este artigo tem como finalidade apresentar uma parte da pesquisa sobre a temática indígena no ensino de história, realizada no Mestrado Profissional de Práticas de Educação Básica nos anos de 2014-2016. O objetivo principal da pesquisa foi compreender como ocorre a inserção da lei 11 . 645/2008 nos livros didáticos de História para o ensino médio, por meio da análise do guia ao professor de História do ensino médio do Plano Nacional do Livro Didático - PNLD, de 2015. Assim procurou-se refletir de que forma as resenhas feitas pelos pareceristas apresentam a temática indígena.

A metodologia utilizada neste trabalho foi a documental, tendo em vista as análises dos pareceristas presentes/encontradas no último Programa Nacional do Livro Didático - PNLD 2015. Buscou-se perguntar e entender como esses pareceristas relacionam a inclusão das questões indígenas à aprovação dos livros didáticos. A fonte documental utilizada foi o guia PNLD para o Ensino Médio 2015, no qual foram investigados e interpretados os dados encontrados nas resenhas das coleções didáticas em que os pareceristas registraram a relevância do ensino de História dos povos indígenas brasileiros nos livros didáticos aprovados.

\section{A temática indígena e a História do Brasil}

Os índios no Brasil estão divididos em diversas etnias, línguas e territórios. Segundo os dados do censo demográfico do IBGE de $2010^{2}$, a população indígena se encontra espalhada por toda área brasileira. Eles estão no interior da floresta Amazônia, como São Gabriel da Cachoeira, assim como estão na maior cidade do país, São Paulo, e também em Brasília, capital do país. O último censo do IBGE apontou que, no Brasil, os indivíduos que se autodeclararam indígenas são 817.963, dos quais 502.783 são moradores da zona rural e 315.180 habitavam as zonas urbanas brasileiras.

A partir da metade do século XX, os povos indígenas começaram a se organizar e a conquistar maior atenção na História do Brasil, influenciando a realidade e repercutindo em suas reivindicações, junto ao poder público, para uma implementação justa e concisa de seus direitos. Eles passaram a lutar

2 Segundo o site do IBGE, o Censo 2010 é um retrato de corpo inteiro do país com o perfil da população e as características de seus domicílios, ou seja, ele nos diz como somos, onde estamos e como vivemos. Disponível em: http://censo2010.ibge.gov.br/sobre-censo.html. Acesso em: 26 de jun. 2017. 
por sua visibilidade, mostrando que não estavam desaparecidos, pois, no passado, foram esquecidos propositalmente: eram considerados selvagens "bárbaros", que deveriam se adaptar à sociedade que buscava um progresso no qual não incluíam culturas diferentes daquilo que, para esse modelo social, era considerado "normal", dentro dessa lógica normalizadora, assim foram excluídos do currículo da educação básica.

John Monteiro (1995) afirma que um novo indigenismo surgiu a partir das reivindicações das organizações indígenas que conseguiram reconquistar direitos históricos. Esse movimento teve apoio dos antropólogos, ocasionando novas produções bibliográficas sobre a temática indígena que até então eram omitidas e gerando novas perspectivas dentro da história do Brasil. A respeito dessas novas produções acadêmicas, John Monteiro (2001) denominou de Nova História Indígena a reconstrução do processo histórico, a revisão de estudos e a inserção do indígena como ator político e atuante nos processos históricos. Como parte desse movimento vários autores são citados. Manuela Carneiro da Cunha (1985), Luis Grupioni (1995) e João Pacheco de Oliveira (1999) apresentam reflexões seminais sobre a temática.

A reivindicação étnica dos indígenas contra os estereótipos existentes em nossa sociedade é uma busca que também inclui repensar a história do Brasil, como a discriminação contra os índios em diversos contextos históricos. Por isso, esta reflexão procura contribuir para o estabelecimento de políticas favoráveis de garantia e de legitimidade dos seus direitos.

Heloisa Bertol Domingues (1989) realizou em sua dissertação uma pesquisa sobre a construção e as relações no IHGB. Segundo a pesquisadora, o historiador Varnhagen não admitia que os índios fossem chamados de brasileiros, para ele, a denominação certa era homem fera, ele também acreditava que os indígenas só poderiam ser conquistados por meio da violência e, desta forma, os bandeirantes tiveram um papel fundamental para a construção da sociedade brasileira "civilizada". Domingues ainda afirma que oposição de civilização e barbárie foi o motivo do debate sobre índios no processo de construção da História do Brasil, mas não a sua razão.

Por sua vez, Francisco Adolfo Varnhagen (1857 apud MONTEIRO, 1995), principal historiador do Brasil durante o período imperial, alinhado à história positivista e evolucionista, marcos intelectuais do século XIX, desenvolveu um conjunto de obras importantes sobre a construção da História do Brasil e da identidade nacional. Varnhagen demonstrou, em sua obra, o preconceito contra os indígenas, postulando que este povo não tinha história e negando a existência de um genocídio no Brasil contra 
as populações originárias ${ }^{3}$.

Para o historiador, o Brasil era a extensão de Portugal. Por isso, ele considerava o português o grande herói, o desbravador das terras. A célebre frase de Varnhagen sobre os índios, "não há história, há apenas etnografia" (VARNHAGEN, 1857 apud MONTEIRO, 1995, p. 28), parece ter sido incorporada na historiografia brasileira por décadas, tendo como desdobramento o preconceito pela da população brasileira em relação aos povos indígenas. Como Paulo Knauss (1991, p. 43) afirma:

Trata-se do maior clássico da historiografia do Brasil, a História Geral do Brasil de Francisco Adolfo Varnhagen, o Visconde de Porto Seguro. Sua obra veio a público entre os anos de 1854-57 e, desde então, se tornou um marco na historiografia nacional, não só por seu resultado interpelativo, mas especialmente, pela diversidade e riqueza no trabalho e erudição em relação às fontes primárias apresentadas ao longo dos seus cinco tomos. A partir de seu engajamento no projeto político de construção da nacionalidade do Império do Brasil, a obra de Varnhagen assumiu desde a sua divulgação, grande importância, tornando-se um alicerce da memória nacional, até os dias de hoje, em grande parte. Questioná-la, acima de tudo, significa pôr em cheque quase todo o discurso exigido acerca do passado colonial do Brasil.

Contrapondo-se ao pensamento de Varnhagen, também no século XIX, o professor do Colégio Pedro II, Capistrano de Abreu, escreveu importantes obras sobre como os portugueses moldaram a América ${ }^{4}$. Esse autor traçou os caminhos do aldeamento e, ao contrário de Varnhagen, tinha uma visão positiva dos índios. Para o autor, o Brasil não era português e sim mestiço (KNAUSS, 1991).

Entretanto, Varnhagen era o principal historiador do IHGB e formulador da ideia de Brasil nação contínua a Portugal. Dessa forma, se criou e se perpetuaram na história brasileira equívocos e termos fantasiosos a respeito das populações originárias, reafirmando uma perspectiva eurocêntrica. Knauss ressalta, ainda, que nem sempre se tem avançado em igual proporção na superação de tal perspectiva oitocentista no âmbito do senso comum, especialmente no que tange aos acontecimentos do século XVI (KNAUSS, 1991). João Pacheco de Oliveira (2010) afirma:

3 Dentre as obras do historiador Varnhagen, podemos destacar: VARNHAGEN, F. A. História Geral do Brasil antes de sua separação e independência de Portugal. 3 vols. São Paulo: Melhoramentos, 1978[1854].

4 Podemos destacar como uma das principais obras de CAPISTRANO DE ABREU, J. Prefácio à História do Brasil. Ensaios e Estudos (Crítica e História). Rio de Janeiro, Livraria Briguiet, 1932. 
A história do Brasil como é habitualmente contada torna inteiramente impossível pretender compreender a importância dos indígenas na fundação da colônia e na construção da nacionalidade inviabilizando igualmente os esforços de entendimento de sua presença e significação na contemporaneidade (p. 28).

Portanto, consideramos importante a ideia de repensar a História do Brasil, seu processo de colonização e as suas contradições, refletir sobre ensino de História, para que se perceba o perigo de uma História única e singular, com a narrativa eurocêntrica e com pouca importância aos indígenas. É preciso, então, rever a multiplicidade de sujeitos, dado que a História é composta por diversos segmentos e agentes sociais.

É o caso do recente livro “O Brasil que os europeus encontraram” (PINSKY; MESGRAVIS, 2014) que procura caracterizar como era o Brasil em 1500. Utilizando como fonte relatos de cronistas da época, como jesuítas, senhores de engenhos e viajantes, o livro busca realizar um resgate legítimo da História, apresentando as primeiras impressões dos portugueses a respeito da terra, da fauna e dos povos que aqui habitavam. No primeiro capítulo, as autoras fazem um minucioso resgate acerca dos povos indígenas, relatando sobre suas etnias, os territórios ocupados e a forma como viviam. As autoras também destacam como os nativos reagiram ao contato com os europeus e quais foram os desdobramentos deste contato, além de abordar as divisões de trabalho e as organizações dos povos autóctones, bem como a questão cultural das guerras e da antropofagia. Posteriormente, destacou-se a importância das missões jesuítas, dos aldeamentos e da catequização como destruidores da cultura indígena e da disponibilização da sua mão-de-obra para o trabalho forçado na colonização.

As historiadoras mostram que, para a sobrevivência, os indígenas tinham que escolher entre serem pacificados ou migrarem para áreas mais afastas, ainda desconhecidas. Vale destacar que não há um estereótipo indígena nesse livro, ao contrário, elas desmistificam a questão da preguiça em relação ao trabalho, apontam que o trabalho escravo indígena existiu até a abolição e que a construção do Brasil em relação ao mito da raça é falsa. As autoras também desconstroem o mito do bandeirante, argumentando que não havia nada de heroico neste tipo de trabalho e, relatando os primeiros anos de colonização no Brasil, procuram dar um novo olhar na História do Brasil.

Pesquisas realizadas nos principais centros universitários brasileiros têm trazido à tona os povos indígenas como protagonistas da história do Brasil. Percebe-se nesses novos estudos a inserção da temática indígena como importante área de estudo da historiografia brasileira, com o objetivo de entender e compreender o processo de ocupação e desenvolvimento territorial do Brasil colônia. A 
pesquisa de João Azevedo Fernandes apresenta uma visão diferenciada sobre os povos indígenas. O historiador e antropólogo, falecido no ano de 2014, realizou um trabalho minucioso em "Selvagens Bebedeiras: álcool, embriaguez e contatos culturais no Brasil Colonial (séculos XVI - XVII)", em que mostra a importância da cauinagem para os povos nativos (FERNANDES, 2011).

Nessa obra inovadora, João Fernandes realizou uma investigação sobre o regime etílico pelos povos indígenas na época dos primeiros contatos com os europeus. Utilizando como fonte os relatos de jesuítas e capuchinhos, do mesmo modo que os cronistas, os viajantes e os residentes do período colonial, Fernandes apresenta os rituais de bebedeiras realizados pelos nativos. O autor fez uma releitura da ideia de que a bebida destruiu a cultura indígena, de que foi utilizada como uma arma na colonização do território que hoje é o Brasil. Em outras conquistas e colonizações, os portugueses utilizaram suas bebidas como formas de submeter outros povos ou de construir alianças, mas no território da América Portuguesa, as bebidas portuguesas não tiveram inserção.

No livro "Negros da Terra", o historiador John Monteiro desenvolveu a história por trás dos bandeirantes, consagrados pela historiografia tradicional brasileira, e procurou demonstrar que a mercadoria que era caçada pelos sertanistas era os povos indígenas das mais variadas etnias (MONTEIRO, 1994). Ao mostrar a importância do papel do índio no ciclo econômico e social de São Paulo, no século XVI, Monteiro rompeu com a historiografia tradicional e criou uma nova temática, a nova história indígena. Por meio de inventários, registros das câmaras municipais e leis, Monteiro traçou o panorama do enriquecimento de certas famílias paulistas atreladas à mão-de-obra indígena.

No livro "Tupinambás, os senhores do Litoral", o historiador Mario Maestri (2013) produz uma história minuciosa que descreve como procedeu e se desenvolveu o contato dos europeus, portugueses e franceses, principalmente, com os indígenas da etnia Tupinambá. A diversidade étnica das populações indígenas no período da conquista portuguesa do território era bastante rica. Os Potiguaras, por exemplo, habitavam as regiões do Maranhão, Ceará, Rio Grande do Norte e Paraíba. Já os Caetés se encontravam desde o Rio Paraíba até o São Francisco. Os Tupinambás ocupavam as regiões do Pará, Maranhão, do Rio São Francisco até o Rio das Contas, enquanto os Tupiniquins residiam desde o Rio das Contas até o Espírito Santo. Os Goitacazes ocupavam do litoral do Espírito Santo ao rio Paraíba do Sul, os Tamoios ocupavam a região do Estado do Rio de Janeiro e os Goianases dominavam de Angra dos Reis à Ilha de Cananeia. Por fim, os Carijós e os Guaranis ocupavam a Ilha de Santa Catarina.

O livro organizado por Luiza Wittmann (2015), professora da UDESC, “Ensino d(e) história 
indígena", apresenta uma coletânea de artigos imprescindíveis para a compreensão da temática indígena na história. Dividido em cinco artigos, cada qual escrito por um autor, traça uma micro história da temática indígena em um determinado tempo e lugar na História do Brasil. Diante desse todo, compreendemos que a história indígena é diversa, que há uma grande quantidade de protagonistas indígenas na nossa História e o quanto precisamos viabilizar isto.

É preciso, portanto, desmistificar o senso comum sobre a dificuldade de se trabalhar com a história indígena, afirmando a não existência de fontes, pois o que se pode perceber é que há arquivos repletos relatando ocupações, guerras sobre as populações indígenas. Sendo assim, precisamos definir que História do Brasil queremos construir, que História do Brasil queremos incluir, se queremos que todas as minorias façam parte desta nação ou se queremos criar uma história seleta. Acredita-se que todo professor de História deva se fazer essa pergunta ao lecionar, pois é preciso incluir e dar voz aos mais variados sujeitos desta História e, dentro disto, é preciso incluir o sujeito indígena.

\section{O Ensino de História e a Lei 11.645/2008}

Sabemos que a História é plural, ela é a história do homem e este é múltiplo. Sabemos também que é importante a construção da identidade no ensino de História e que esta identidade deve ser composta das diferentes histórias e sujeitos. Dessa maneira, ao refletirmos sobre a História do Brasil, podemos observar que, até a primeira metade do século XVI, é possível considerar que o território da América portuguesa não estava oficialmente dividido, pois a prática de escambo não garantia a ocupação permanente. Durante um longo período, a chegada dos portugueses ao território foi denominada descoberta. Por séculos, esse foi o termo utilizado nas instituições universitárias e nas escolas básicas, ainda permanecendo no imaginário da população brasileira. Hoje se utilizam termos como encontro de culturas, encontro de civilizações, mas muito se trata das sociedades europeias e pouco se apresenta e se estuda sobre a história das populações originárias do Brasil.

O conhecimento escolar é a construção do conhecimento a partir de uma tradição seletiva do currículo. O professor, ao lecionar, faz uma mediação didática, adequando diversos saberes ao saber ensinado, tentando, de fato, aproximar o conhecimento histórico à realidade atual. Precisamos utilizar referências do presente, como analogias que possam fazer um elo com o conteúdo ensinado. Ensinar História, portanto, é gerar um compromisso com a reflexão dos fatos, conceitos e tempo histórico. O objetivo do ensino da História é a construção do conhecimento do homem no tempo. Os professores possuem a responsabilidade de trazer esse conhecimento de forma que interesse aos 
alunos. É preciso, então, compreender as especificidades da história por meio da prática docente. Dessa forma, mostrar a relação entre o passado e presente. 0 ensino de História é indispensável para a compreensão da sociedade atual, na qual o professor tem principalmente um papel político, isto é, ele precisa fazer com que o aluno reflita sobre a sua conjuntura política e socioeconômica.

De acordo com Ana Maria Monteiro, "Os professores de História não apenas detêm saberes especializados, mas também os produzem e reproduzem, ao adequá-los ao grau de compreensão dos alunos" (MONTEIRO, 2009. p. 15). Destacam-se as funções do professor de criar e se adaptar às transformações que a sociedade vive: ao tentar dialogar com o conhecimento, o professor possui os seus saberes e os transforma a cada experiência.

A descoberta do Relatório Figueiredo, assim como os relatórios da Comissão da Verdade são novas fontes sobre a relação do Estado Brasileiro com as populações indígenas na contemporaneidade, mostrando que a violência não ficou somente no passado. Em março de 2008, a lei 11.645/2008 foi promulgada pelo presidente Luiz Inácio Lula da Silva, passando a reconhecer a temática da história indígena como importante matriz da sociedade brasileira e representando um avanço nesta discussão. Assim, a percepção dessa promulgação deve ser incorporada na prática cotidiana da sala de dos professores de história. Como Silva (2015, p. 21) afirma:

a lei 11.645/2008, que prevê a inserção do ensino de história e culturas indígenas na educação básica, representa um passo enorme em direção ao reconhecimento de uma sociedade historicamente formada por diversas culturas e etnias, dentre elas as indígenas. Afinal, o Brasil é um país de rica diversidade pluricultural e multiétnica.

A reflexão acerca da promulgação dessa lei é um desafio para todos que atuam na educação. Entretanto, deve-se admitir que existe um despreparo para os professores sobre a temática, igualmente a abordagem ainda tímida do tema nas diferentes universidades, contribuindo desta forma para a lacuna sobre o ensino de História indígena com os licenciandos que, no futuro, atuarão como professores de educação básica.

Na América portuguesa, a palavra índio servia para designar as mais diversas etnias, grupos e culturas nativas existentes no território. Posteriormente, se criou as denominações de Tupi e Tapuia. Segundo o historiador Monteiro (1995), os Tupi eram os povos do litoral de Santa Catarina ao Maranhão. Tapuia, diferenciados socialmente do padrão Tupi, eram pouco conhecidos dos europeus e se encontravam nos sertões do território. Dessa maneira, o próprio historiador afirma que os europeus do século XVI procuraram reduzir o vasto panorama etnográfico em apenas duas categorias: 
Tupi e Tapuia. A execução e a preocupação com a lei 11.645/2008 é de extrema importância, pois mesmo com sua existência desde 2008, ainda há uma inserção muito pequena sobre os povos indígenas nos livros didáticos.

Ao lecionar História para as séries do ensino básico, percebe-se que os livros didáticos não são frequentemente atualizados e acabam ficando muitas vezes defasados na utilização de conceitos e no tratamento dado às fontes históricas. Alguns livros tornaram-se, inclusive, obsoletos. $\mathrm{O}$ que ocorre é a distância do conhecimento universitário em relação ao ensino básico, como Souza Lima (1995) afirma:

Os indígenas permanecem como povos ausentes, imutáveis, dotados de essências a-históricas e objetos de preconceito: nunca saem dos primeiros capítulos dos livros didáticos são, vaga e genericamente, referidos como um dos componentes do povo e da nacionalidade brasileiros, algumas vezes tidos como vítimas de uma terrível "injustiça histórica". Os verdadeiros senhores da terra. Não surgem enquanto atores históricos concretos, dotados de trajeto próprio, participantes de guerras pelo controle de espaços geográficos específicos, inimigos, mas também muitas vezes aliados, beneficiários e instrumentos dos conquistadores, presentes até hoje em tudo o que se passa em muitas regiões do Brasil (p. 408).

Dessa maneira, observa-se que o indígena é tratado como sujeito secundário, um mero coadjuvante da história do Brasil, sem participação política ativa, apenas como um povo sem história e sem futuro. Essa visão ainda é mantida de forma sutil nos currículos, nos livros, na escola.

\section{A política do livro didático no Brasil}

Há muitas pesquisas que procuram analisar os componentes curriculares nos livros didáticos. Fonseca (2003) afirma que muitos livros didáticos não acompanham a produção dos novos conhecimentos na área de história e de antropologia, ficando apenas atrelados à indústria editorial. A produção editorial de livros didáticos do Brasil, segundo o autor, é uma das maiores do mundo.

Oliveira (2009) afirma que há uma disputa sobre o que é o livro didático. Para os autores desse material, ele é suporte da disciplina escolar, em que se planeja e organiza uma situação didática. O livro didático é a tecnologia educacional difundida no século XIX mais presente no cotidiano escolar.

Os livros didáticos, a partir da década de 1970, exerceram, simultaneamente, a função de portadores de determinados conteúdos e organizadores de aula. O livro didático passou a ocupar papel central no processo ensino-aprendizagem (GATTI JUNIOR, 2004). Porém, como o livro didático se 
tornou um instrumento tão importante em nossa sociedade? Certamente, uma importante pista está no primeiro programa desenvolvido pelo governo federal em relação ao livro didático, durante a década de 1930. A primeira medida pensada e criada pelo governo de legislar e controlar o livro didático ocorreu em 1938, com a Comissão Nacional do Livro Didático (CNLD). Ela não foi, entretanto, bem-sucedida, pois não teve um número adequado de integrantes para análise de toda a produção de livros didáticos no Brasil (OLIVEIRA; GUIMARÃES; BOMÉNY, 1984).

O objetivo da CNLD era que cada livro aprovado tivesse seu próprio selo de aprovação, acompanhado de um registro especial. Pode-se observar que no atual Programa Nacional do Livro Didático (PNLD) também existe a permanência desses mesmos itens. É importante salientar que a criação da CNLD está inserida no contexto do Estado Novo, no qual havia uma preocupação aparente com a transmissão de novos ideais, que deveriam estar presentes nos livros didáticos, importantes portadores e transmissores desse novo modo de vida.

Miranda e Luca (2004) argumentam que os governos autoritários utilizaram a educação como forma de promover sua política e de criar cidadãos passivos, por meio de programas envolvendo os livros didáticos. Também na ditadura militar houve incentivos como subsídios às editoras, que cresceram acentuadamente no mercado dos livros didáticos.

Por sua vez, a criação do PNLD, em 1985, marcou uma nova forma de pensar a produção do livro didático vinculado à educação brasileira. Em 1995, surgiu o atual PNLD com duas funções: melhorar a qualidade da educação e suprir a necessidade de distribuição gratuita de livros a todas as escolas públicas do país (AQUINO, 2013). Assim, a partir de 1996, todos os estudantes do ensino fundamental das escolas públicas adquiriram o direito de receber os livros didáticos gratuitamente.

Os livros didáticos são ferramentas das políticas educacionais e revelam, em seu processo de produção, circulação e consumo, as disputas que emergem no campo do currículo. $O$ atual PNLD possui um guia de Livros Didáticos com resenhas das coleções oficialmente aprovadas. Esse guia é encaminhado às escolas para que os professores escolham o livro que consideram o mais adequado para a utilização em sala.

O livro didático se constitui como uma importante fonte de pesquisas, tendo como referência o PNLD, o maior programa de distribuição de livros didáticos do mundo. Além disso, o livro didático é um recurso pedagógico amplamente utilizado nas escolas públicas na atualidade.

Compreende-se que os livros didáticos são ferramentas importantes que possibilitam a 
produção, circulação e consumo das políticas curriculares para o ensino básico e que é nele que se pode observar a disputa de currículo, definidora do que se deve incluir no aprendizado da educação básica. O livro didático é um produto cultural e pode ser utilizado de diversas formas, já que são portadores de determinados conteúdos e muitas vezes são organizadores das aulas, ocupando papel central no processo ensino-aprendizagem. Muitos professores se guiam por ele para lecionar enquanto outros utilizam esse material didático como uma ferramenta.

É frequente que, a cada governo, a política estatal do livro seja modificada, por isto, é presente a disputa pelo currículo oficial, pelo que ensinar, por aquilo que deve estar presente no currículo oficial e, consequentemente, nas coleções didáticas. O livro didático também é uma mercadoria valiosa na qual está inserido o currículo proposto do governo. Os livros didáticos representam mais de $50 \%$ da venda de livros no Brasil (CASSIANO, 2007), por causa disto, Mattos (2012) destaca que o livro didático, antes se ser um recurso didático, é um produto comercial inserido em políticas públicas da educação nacional.

Desse modo, o livro didático, ponto comum entre o professor e o aluno, tem se tornado presente e mediador no ensino e aprendizagem por décadas nas escolas. O livro didático contribui para a reprodução de estruturas do pensamento dominante, pois, para o pesquisador o mercado editorial é o mais poderoso instrumento de reprodução normalizadora do saber (KNAUSS, 2009). Segundo Schimidt e Cainelli (2009), todos os livros didáticos necessitam serem compreendidos por seu processo de produção, distribuição e consumo.

Para Oliveira (2009), é de grande importância a avaliação do Ministério da Educação sobre o livro didático, pois ele era visto com alguns problemas, relacionado à baixa qualidade da educação. Para a pesquisadora, o valor do livro didático engloba os aspectos pedagógicos, econômicos, políticos e culturais. Ele precisa, assim, ser entendido como parte da história cultural de nosso tempo, e que, na relação ensino aprendizagem, o livro didático é objeto de vários sujeitos.

De acordo com Gabriel (2009), o livro didático se tornou um elemento poderoso e determinante no ensino básico brasileiro. O livro didático de História hoje é um canal privilegiado de difusão de conhecimento, mas também de distribuição e consumo de saberes híbridos. A presença de diferentes discursos pedagógicos e históricos é uma de suas marcas mais evidentes na disputa pelos sentidos da história a ser ensinada na educação básica. Choppin (2004) enfatiza que os livros didáticos não são somente ferramentas pedagógicas, mas também possuem suas ideologias e são fonte abundante para pesquisa. 
A avaliação do PNLD ocorre desde 2001 sob a responsabilidade direta das universidades públicas, havendo, portanto, uma política do MEC de intervenção editorial e de controle sobre o que é produzido em materiais didáticos. É uma política de Estado na qual o governo federal procura socializar e dinamizar a educação no país. Essas avaliações, apesar de serem recentes, fizeram com que o mercado editorial se reajustasse às demandas atuais, evitando estereótipos e preconceitos.

As coleções didáticas são analisadas por diversos pareceristas, que avaliam se os livros foram adequados de acordo com as vigências do currículo, das demandas dos programas oficiais e das leis, a saber, a lei 11.645/2008, que define a obrigatoriedade do ensino de história da África e da história dos povos indígenas do Brasil. De acordo com esses critérios, os livros didáticos não devem trazer preconceito ou estimular a violência. ${ }^{5}$

A influência do governo na seleção dos livros que compõem o Guia do livro didático demonstra que as coleções estão comprometidas com demandas do programa oficial (MATTOS, 2012), pois os livros acabam se tornando iguais, tendo os mesmos padrões e abordagens, frutos da idêntica demanda de consumo das políticas de Estado. Assim, os editores de livros didáticos pouco ousam, criando uma padronização nos conteúdos, na metodologia e na estrutura.

O Guia do PNLD possui um valor simbólico no qual as resenhas desenvolvidas pelos pareceristas influenciam diretamente no processo de seleção dos professores de educação básica das escolas públicas de todo Brasil (MATTOS, 2012). O Guia é, portanto, um instrumento importante para as reflexões e, diante disto, o percurso de análise se centra no último Guia do PNLD para o Ensino Médio de 2014, particularmente nas análises dos pareceristas sobre a inclusão da lei 11.645/2008, foco do artigo.

Assim, enfatizamos a importância deste estudo, ao analisar como os livros didáticos incorporam a lei 11.645. /2008 Esse pode ser um recorte complexo, já que o currículo é feito de escolhas, em um processo político. O livro pode ser considerado um dos protagonistas da educação básica, já que o governo gasta uma média de 780 milhões de reais ao mercado editorial em cada edição do PNLD (VAZQUEZ, 2014). Cabe, então, afirmar que a política do livro didático é uma política de Estado

5 O edital do PNLD 2015 pode ser consultado no seguinte endereço eletrônico. Disponível em: <http:/www.fnde.gov.br/programas/livro-didatico/livro-didaticoeditais/item/4032-pnld-2015>. Acesso em: 26 jun. 2017. 
e que nela há critérios e exigências (CERRI; FERREIRA, 2007), por meio dos quais avaliadores, de forma minuciosa e sigilosa, analisam diversos itens que devem compor a obra didática.

O uso do livro didático não deve ser discutido somente por professores da educação básica; a discussão acerca do seu uso necessita ser ampliada às universidades. Os cursos de licenciatura precisam perceber que os livros didáticos serão um importante instrumento no futuro de seus alunos e que os estudantes carecem de ter entendimento e crítica a seu respeito. Sabemos da resistência ou dificuldade da universidade em tratar o livro didático como uma fonte de estudo, porém, há novos estudos, tanto no campo da educação quanto do ensino, que procuram problematizar a relação do livro didático com os saberes dos professores e compreender sua importância na educação básica.

Os livros didáticos são produtos culturais e, portanto, são consumidos por seus leitores. Deve-se então analisar o que essas obras estão produzindo no âmbito da lei 11. 645, já que este é um item de análise do PNLD. Afinal, os estudantes estão consumindo esses conteúdos e, consequentemente, gerando opiniões e ideias em relação às etnias indígenas. Além disso, o livro didático é muitas vezes o único livro que o estudante possui em casa. Por isso, é preciso reconhecer a importância desse programa de distribuição em todas as regiões do Brasil. O livro didático é importante por seu papel político e cultural, à medida que reproduz e representa os valores da sociedade (GATTI JUNIOR, 2004).

Na pesquisa sobre o livro didático de História no Brasil, Gatti Junior (2004) analisa como os livros didáticos são fabricados. Ele enfatiza que o livro didático ocupa um papel central no processo de ensino-aprendizagem. $O$ historiador alega que assim como as escolas nunca foram iguais para todos, os livros didáticos também não eram. Eles seriam elaborados segundo os padrões socioeconômicos estabelecidos, desta forma perpetuando a desigualdade em nossa sociedade.

Os livros didáticos tinham um destaque menor até a década de 1960. Mas a partir da década de 1970, com a ampliação das escolas e com a entrada de novos atores sociais, tornou-se indispensável, uma vez que uma nova realidade escolar estava sendo implementada. O livro didático teve, então, sua linguagem renovada, com um vocabulário mais próximo ao do público leitor.

Como os livros didáticos são elaborados? Quem são seus autores? Décio Gatti procura responder a essas perguntas ao entrevistar uma diversidade de autores de livros didáticos de história. Os autores são formados em História e se mantiveram vinculados à área de história e a de educação. Para o pesquisador, o livro didático com um êxito intelectual alto teria pouco êxito comercial, os livros prediletos pelos acadêmicos não são os mais usados nas escolas. Essa questão mostra o quanto o 
conhecimento acadêmico às vezes está distante do conhecimento didático escolar.

No artigo, "Professores e livros didáticos: narrativas e leituras no ensino de história", Monteiro (2009) argumenta que os livros didáticos interpretam as orientações oficiais, assim como os professores não são meros aplicadores destas diretrizes oficias. Além disso, a autora ainda afirma:

Os autores, ao produzir livros didáticos, interpretam as orientações oficiais, ou seja, as reelaboram segundo suas ideias pedagógicas e, ao mesmo tempo, incorporam expectativas dos professores, buscando atraí-los para o seu consumo (MONTEIRO, 2009, p. 176).

Os livros didáticos, segundo essa autora, assumem diferentes funções: a referencial, sendo depositário dos conhecimentos propostos nos programas de ensino; a instrumental, com a sua prática de exercícios propostos; a ideológica e cultural, presente há tempos nas coleções didáticas, na qual se destaca como instrumento privilegiado na construção das identidades dos estudantes como futuros cidadãos e; a função documental, importante componente pelo conjunto de documentos apresentados aos estudantes podendo desenvolver o espírito crítico destes. Essas funções mostram o quanto o livro didático é imprescindível nas salas de aula e como é um componente escolar importante o qual deve ser estudado e pesquisado.

Gabriel (2009) aprofunda a questão do livro didático de História como um artefato cultural no qual os discursos são disputados e legitimados pelo currículo. Nesse sentido, o discurso predominantemente presente nos livros didáticos é o oficial. Segundo Gatti Junior (2004), o Estado Brasileiro está presente no currículo prescrito, pois é na política do governo em relação ao livro didático que o currículo presente é inserido e escolhido. Assim, os currículos são escolhas de acordo com os contextos políticos.

O texto dos Parâmetros Curriculares Nacionais (PCN) (1998a, 1998b) inaugura um novo papel do Estado na política, o de centralizar os conteúdos escolares nacionais. O Estado passa a orientar os conteúdos que devem ser trabalhados nas disciplinas da educação básica, como também nos temas transversais, direcionando professores e escolas à interdisciplinaridade. Freitas et al. (2007) considera que não há um livro ideal, pois sempre haverá divergências sobre os projetos pedagógicos presentes nos livros didáticos. Cabe ao professor escolher o melhor livro de acordo com as particularidades de seus alunos, de sua escola, de sua região.

Para Silva (2007), por causa do PNLD, a escolha do livro didático se tornou algo inerente à função do docente. Essa autora entende que os diferentes usos do livro didático dependem sempre 
da formação e da preparação do docente frente ao processo de ensino-aprendizagem. A autora ainda alerta para uma preocupação em relação à desqualificação do professor sem a reflexão anterior ou posterior ao livro didático. Para tal, ela considera relevante que "os cursos de licenciatura em História abordem de forma consistente uma reflexão sobre o processo de formação docente e sua atuação na escola" (p. 64). Portanto, o livro didático deve ser objeto de pesquisa nos cursos de licenciatura. É preciso repensar o seu uso e refletir sobre suas propostas.

\section{O PNLD de História 2015}

Na avaliação do PNLD para a disciplina História, destinada ao Ensino Médio de 2015, foram aprovadas 19 coleções didáticas. Delas, treze já pertenciam ao programa na última avaliação, outras seis editoras tiveram seus títulos aprovados pelo programa pela primeira vez, o que é válido, pois diversifica as coleções para a escolha do professor. Porém, ao analisarmos as resenhas dos pareceristas, percebemos que nem todas as coleções contemplam a temática indígena em seus três volumes. Ainda assim, podemos considerar relevante que a coleção de livros mais distribuída por todo o território brasileiro contenha a inserção da temática indígena em todos os seus volumes, sendo a coleção "História e Sociedade", da Editora FTD, que teve a sua primeira edição para o Ensino Médio.

A Editora Saraiva conseguiu três coleções didáticas aprovadas, sendo que o título "História para o Ensino Médio" teve a sua primeira edição incluída na lista. As Editoras Ática e Scipione permaneceram, cada, com uma coleção. Já a Editora Positivo obteve duas coleções aprovadas, uma já pertencente ao programa e outra nova. As Editoras Brasil, SM, Escala Educacional, Base Editorial e Companhia da Escola permaneceram com as suas únicas coleções e mantiveram a aprovação do programa desde, pelo menos, a última avaliação. A Editora FTD alcançou duas coleções aprovadas, sendo que uma foi primeira edição, a Editora Moderna logrou as duas coleções inscritas aprovadas e as Editoras AJS, Leya e IBEP foram aprovadas pelos pareceristas do PNLD na disciplina de História pela primeira vez e cada uma conseguiu uma coleção ingressando pela primeira vez no programa. De acordo com a análise feita para o guia, pelo pelos pareceristas, percebemos que alguns livros didáticos foram aprovados sem contemplarem, em sua totalidade, a Lei 11. 645 (BRASIL, 2008), que em seus dois artigos ressalta que:

Art. 10 0 art. 26-A da Lei no 9.394, de 20 de dezembro de 1996, passa a vigorar com a seguinte redação:

Art. 26-A. Nos estabelecimentos de ensino fundamental e de ensino médio, públicos e privados, torna-se obrigatório o estudo da história e cultura afro- 
R. A. MELLO

brasileira e indígena.

$\S 1$ O O conteúdo programático a que se refere este artigo incluirá diversos aspectos da história e da cultura que caracterizam a formação da população brasileira, a partir destes dois grupos étnicos, tais como o estudo da história da África e dos africanos, a luta dos negros e dos povos indígenas no Brasil, a cultura negra e indígena brasileira e o negro e o índio na formação da sociedade nacional, resgatando as suas contribuições nas áreas social, econômica e política, pertinentes à história do Brasil.

$\S 2$ O Os conteúdos referentes à história e cultura afro-brasileira e dos povos indígenas brasileiros serão ministrados no âmbito de todo o currículo escolar, em especial nas áreas de educação artística e de literatura e história brasileiras. (NR)

Art. 2o Esta Lei entra em vigor na data de sua publicação.

De acordo com a lei 11. 645, a cultura indígena e sua história devem aparecer nas áreas social, econômica e política, pertinentes à História do Brasil, porém não há o critério cronológico específico e sim a afirmação que ela deva estar incluída em todo o currículo escolar de História brasileira. Para a coleção "Caminhos do Homem", da Editora Base Editorial, os pareceristas observam no quesito "Em sala de aula":

Ao abordar a História dos grupos indígenas nas diversas sociedades, formulam- se algumas generalizações sobre seus modos de vida. Seria importante buscar referências mais atualizadas sobre tal temática, principalmente em relação a questões contemporâneas (BRASIL, 2014, p. 28).

Tal trecho sugere que, apesar de a coleção incorporar a lei 11. 645, a forma por meio da qual a mesma o faz não é a mais adequada e que o professor deverá buscar material fora da coleção didática. Outro livro aprovado pelo PNLD 2015 que não incorpora a lei 11. 645 na totalidade dos conteúdos curriculares é "História em debate", da Editora do Brasil, para o qual os pareceristas informam no "Projeto Gráfico editorial":

Nas representações visuais há poucos exemplos de imagens de afrodescendentes e descendentes das etnias indígenas brasileiras em diferentes profissões, trabalhos e espaços de poder na atualidade (BRASIL, 2014, p. 55).

Assim como na análise do quesito "Em sala de aula":

Professor: Com relação à cultura e à História da África, dos afrodescendentes e dos indígenas no Brasil, sugere-se que você aprofunde a discussão sobre o papel político desses povos no Brasil contemporâneo (BRASIL, 2014, p. 55). 
A terceira coleção que necessita a busca de outros recursos didáticos para uma melhor abordagem sobre os povos indígenas na contemporaneidade é a "História em Movimento", da editora Ática, para a qual os pareceristas informam:

Professor: No que se refere aos povos afro-brasileiros e os indígenas, para contornar a compartimentalização da abordagem, e visando à sua integração aos conteúdos de modo geral, será importante buscar referências contemporâneas e outros procedimentos de construção do conhecimento histórico escolar a fim de instrumentalizar, na prática didática, o seu local de atuação como fonte histórica ou como recurso e material didático (BRASIL, 2014, p. 61).

A coleção "História Geral e do Brasil" da Editora Scipione é outra coleção que não incorpora a lei 11. 645 em todos os conteúdos curriculares. Os pareceristas afirmam no quesito "Em sala de aula":

Também será interessante buscar outras referências sobre a história das nações indígenas, uma vez que a coleção privilegia discussões da inserção de tais grupos principalmente no período colonial do Brasil (BRASIL, 2014, p. 67).

A coleção "Nova História integrada" da Editora Companhia da Escola é outra que, segundo os pareceristas, precisa de complementação na sala de aula. A análise relata:

Professor: É necessário também que se faça um complemento dos conteúdos de História da África, de cultura afro-brasileira e de História dos povos indígenas, incorporando-os à realidade contemporânea e local do aluno, uma vez que, na coleção, esses conteúdos tendem a ser tratados com referência ao passado" (BRASIL, 2014, p. 93).

A sexta coleção que não inclui a lei 11.645 em todos os conteúdos curriculares é a "Oficina de História", da Editora Leya. No quesito "Em sala de aula”, os pareceristas apontam:

Professor: Há de se ter um cuidado especial no que concerne ao trabalho sobre as populações indígenas, no sentido de procurar alternativas e orientação em outras fontes a fim de complementar as indicações apresentadas na coleção (BRASIL, 2014, p. 105).

A coleção "Ser Protagonista História" das Edições SM, recebe a seguinte ressalva em sua análise:

A pouca visibilidade de indígenas e afrodescendentes em posições destacadas em termos sociais, políticos, econômicos, culturais ou profissionais restringe o aprofundamento da reflexão acerca das lutas e conquistas desses povos ao longo do tempo (BRASIL, 2014, p. 116). 
Diante das análises dos pareceristas, percebemos que das 19 coleções aprovadas pelo PNLD 2015 e que estão em vigor hoje, no ano letivo de 2017, nas escolas públicas de educação básica, sete coleções contribuem para o silenciamento e a invisibilidade dos povos indígenas na atualidade. Acreditamos que esse apagamento colabora para a perpetuação do preconceito contra esses povos e, ainda mais, para a crença que a população autóctone esteja extinta ou que não esteja incorporada ao mundo atual.

Sabemos que a Lei 11.645 não obriga a temática sobre a história indígena em toda sua plenitude cronológica, mas ela obriga a presença em toda a História brasileira, o que não tem ocorrido em todas as coleções didáticas aprovadas pelos pareceristas no PNLD. Diante desse cenário, consideramos importante que as coleções se adequem à totalidade da lei, já que na próxima edição do PNLD para o Ensino Médio a lei estará completando 10 anos de existência.

Sendo assim, consideramos necessário que os livros didáticos de História revisem a temática indígena na contemporaneidade, pois como Nikitiuk (2012) apresenta, a escola é a maior responsável pelo processo de reprodução desigual em nossa sociedade. O ensino de História não deve ser só voltado para o passado, mas refletido sobre o presente.

Dessa forma, os povos indígenas não são vítimas passivas da sociedade, da cultura dominante ou da política na História do Brasil. Devem-se compreender os processos históricos e refletir como os povos indígenas atuaram criando suas estratégias de luta e de sobrevivência, bem como a maneira com que se relacionavam tanto na América portuguesa quanto nos dias atuais.

\section{Referências}

AQUINO, L. V. Avaliação do livro didático, texto de apoio. Material didático impresso. Rio de Janeiro: Programa de Residência Docente, DPPG, 2013.

BRASIL. Instituto Brasileiro de Geografia e Estatística (IBGE). Os indígenas no censo demográfico 2010. Rio de Janeiro: Ministério do Planejamento, Orçamento e Gestão. Disponível em: <http://indigenas.ibge.gov.br/>. Acesso em: 20 abr. 2015.

. Ministério da Educação. Programa Nacional do Livro Didático (PNLD), Brasília, 2015. Disponível em: <http:/www.fnde.gov.br/programas/livro-didatico/livro-didatico-editais/item/4032pnld-2015>. Acesso em: 26 jun. 2017.

. Presidência da República/Subchefia para Assuntos Jurídicos. Lei 11.645, de 10 de março de 2008. Disponível em: <http://www.planalto.gov.br/ccivil_03/_ato2007-2010/2008/lei/l11645.htm>. Acesso em: 11 out. 2017. 
. Secretaria de Educação Fundamental, Parâmetros Curriculares Nacionais (PCN): História. Brasília: Ministério da Educação / Secretaria de Educação Fundamental, 1998a.

Secretaria de Educação Fundamental, Parâmetros Curriculares Nacionais (PCN): terceiro e quarto ciclos: apresentação dos temas transversais - Apresentação \& Pluralidade Cultural. Brasília: $\mathrm{MEC} / \mathrm{SEF}, 1998 \mathrm{~b}$.

. Secretaria de Educação Básica. Guia de livros didáticos: PNLD 2015: história: ensino médio. Brasília: Ministério da Educação, Secretaria de Educação Básica, 2014. 140 p.

CASSIANO. C. C. F. O mercado do livro didático no Brasil: do Programa Nacional do Livro Didático PNLD à entrada do capital internacional espanhol (1985-2007). Tese (Doutorado em Educação). Pontifícia Universidade Católica, São Paulo, 2007.

CERRI, L. F.; FERREIRA, A. Notas sobre as demandas sociais de representação e os livros didáticos. In: OLIVEIRA, M.; STAMATTO, I.(Orgs.), O Livro didático de História: Políticas educacionais, pesquisa e ensino. Natal: Edufrn, 2007. p. 75-85.

HOPPIN, A. História dos livros e das edições didáticas: sobre o estado da arte. Educação e pesquisa, São Paulo, v. 30, n. 3, p. 549-566, 2004.

DOMINGUES, H. B. A noção de Civilização na visão dos construtores do Império. A revista do Instituto Histórico e Geográfico Brasileiro: 1838-1850/60. Dissertação (Mestrado em História). Niterói: ICHF/ CEG/UFF,1989.

FERNANDES, J. A. Selvagens bebedeiras, álcool, embriaguez e contatos culturais no Brasil colonial (séculos XVI- XVII). São Paulo: Alameda, 2011.

FONSECA, S. G. Didática e Prática de ensino de História: Experiências, Reflexões e Aprendizados. Campinas: Papirus, 2003.

FREITAS, I. et al.; A Ação do PNLD em Sergipe e a escolha do livro didático de História (2005/2007): Exame preliminar. In: OLIVEIRA, M.; STAMATTO, I. (Orgs.), O Livro didático de História: Políticas educacionais, pesquisa e ensino. Natal: Edufrn, 2007. p. 53-61.

GABRIEL, C. T. Exercícios com documentos nos livros didáticos de história: negociando sentidos da história ensinada na educação básica. In: ROCHA, H.; REZNIK, L.; MAGALHÃES, M. (Orgs.), A história na escola: autores, livros e leituras. Rio de Janeiro: FGV, 2009. p. 243-249.

GATTI JÚNIOR, D. A escrita escolar da História: livro didático e ensino no Brasil (1970-1990). Bauru: EDUSC/Belo Horizonte: EDUFU, 2004.

KNAUSS, P. O Rio De Janeiro da Pacificação: Franceses e portugueses na disputa colonial. v.18, Rio de Janeiro: Secretaria Municipal de Cultura, Turismo e Esportes, Departamento Geral de Documentação e Informação Cultural, Divisão de Editoração, 1991.

KNAUSS, P. Por onde anda a história na atualidade da escola: ensino médio, livros didáticos e ensino de história. In: ROCHA, H; MAGALHÃES, M.; CONTIJO, R. (Orgs.), A escrita da história escolar: memória e historiografia. Rio de Janeiro: FGV, 2009. p. 293-308.

LIMA, A. C. S. Um olhar sobre a presença das populações nativas na invenção do Brasil. In: SILVA, A. L. S.; GRUPIONI, L. D. B. (Orgs.), A temática indígena na sala de aula. Novos subsídios para professores de 1ํ e 2ํo graus. Brasília: MEC, 1995, p. 407-419. 
MAESTRI, M. Os senhores do Litoral: conquista portuguesa e agonia tupinambá no litoral brasílico século 16. 3. ed. Porto Alegre: UFRGS, 2013.

MATTOS, J. S. Os livros didáticos como produtos para o Ensino de História: Uma abordagem do Plano Nacional do Livro Didático - PNLD. Historiae, v. 3, n. 3, p. 165-184, 2012.

MIRANDA, S. R.; LUCA, T. R. O Livro didático de história hoje. um panorama a partir do PNLD. Revista Brasileira de História, São Paulo, v. 24, n. 48, p. 123-144, 2004.

MONTEIRO, A. M. Professores e livros didáticos: Narrativas e leituras no Ensino de História. In: ROCHA, H.; REZNIK, L.; MAGALHÃES, M. (Orgs.), A história na escola: autores, livros e leituras. Rio de Janeiro: FGV, 2009. p. 151-172.

MONTEIRO, J. Negros da Terra. Índios e bandeirantes nas origens de São Paulo. São Paulo: Companhia das Letras, 1994.

MONTEIRO, J. O Desafio da História Indígena no Brasil. In: SILVA, A. L. S.; GRUPIONI L. D. B. (Orgs.), A temática indígena na sala de aula. Novos subsídios para professores de $1^{\circ}$ e 2 ㅇ graus. Brasília: MEC, 1995, p. 221-228.

MONTEIRO, J. Tupis, tapuias e historiadores. Tese (Livre docência). Universidade Estadual de Campinas, Campinas, 2001.

NIKITUIK, S. (Org.) Repensando o Ensino de História. 8. ed, São Paulo: Cortez, 2012.

PINSKY, C. B.; MESGRAVIS, L. O Brasil que os Europeus Encontraram: a natureza, os índios, os homens brancos. São Paulo: Editora Contexto, 2014.

OLIVEIRA, I. F. Livro didático de história: Definições, Representações e prescrições de uso. In: OLIVEIRA, M.; OLIVEIRA, A. (Orgs.), Livros didáticos de história: Escolhas e atualizações. Natal: Edufrn, 2009. p. $11-21$

OLIVEIRA, J. B. A.; GUIMARÃES, S. D. P.; BOMÉNY, H. M. B. A política do livro didático. Campinas: Editora da UNICAMP, 1984.

OLIVEIRA, J. P. O Nascimento do Brasil: Revisão de um paradigma historiográfico. Anuário Antropológico, p. 11-40, 2010. Disponível em: <https://aa.revues.org/758>. Acesso em: 11out. 2017.

SCHMIDT, M. A.; CAINELLI, M. Ensinar História. São Paulo: Scipione, 2009.

SILVA, G. J. Ensino de História indígena. In: WITTMANN, L. T. (Org.), Ensino d(e) História indígena. Belo Horizonte: Autêntica, 2015. p. 61-67.

SILVA, I. B. O Livro Didático de História e a Formação Docente. In: OLIVEIRA, M. M. D.; STAMATTO, M. I. S. (Orgs.), O Livro Didático de História: políticas educacionais, pesquisas e ensino. Natal: EDUFRN, 2007. p. 61-65.

VAZQUEZ, R. P. Edital PNLD 2011: Sentidos de docência, ensino e línguas. Tese (Doutorado em Letras). Universidade Federal do Rio de Janeiro, Rio de Janeiro, 2014.

WITTMANN, L. T. (Org.), Ensino d(e) História indígena. Belo Horizonte: Autêntica, 2015.

Recebido em: 26/03/2017

Aceito em: 07/08/2017 